\title{
EPIDEMIOLOGICAL TREND IN SUPERFICIAL FUNGAL INFECTIONS AT A TERTIARY CENTRE IN WESTERN UTTAR PRADESH, INDIA
}

\author{
Vaibhav Mangla 1
}

1Postgraduate Resident, Department of Dermatology, SRMS IMS, Bareilly, Uttar Pradesh, India.

\section{BACKGROUND}

\section{ABSTRACT}

It is an indisputable fact that there is an increase in the prevalence of dermatophytosis over the past 4 - 5 years across the country (Prevalence rate $=27.6 \%$ in India and $29.6 \%$ outside India). $1,2,3$ However, the current perception among practicing Indian Dermatologists is that among outpatients there is a huge change in clinical profile, both qualitative and quantitative. ${ }^{1}$

The study was aimed at studying different epidemiological factors, which influence or are likely to influence superficial fungal infections.

\section{MATERIALS AND METHODS}

This was a descriptive study. Patients with suspected dermatophytoses attending the Dermatology Department of SRMS Hospital, Bareilly were enrolled in the study. A detailed history, clinical examination and sample collection for mycological examinations were done.

\section{RESULTS}

Out of 600 patients screened, 150 patients were finally enrolled who fulfilled all inclusion criteria and exclusion criteria.

\section{CONCLUSION}

Our study is a comparative analysis with studies done in other parts of the country to the trends in Western Uttar Pradesh and Uttarakhand on dermatophytosis and superficial fungal infection. Subjects in the age group 21-30 years, service personnel and subjects from upper socio-economic status were more predisposed to superficial fungal infections.

\section{KEY WORDS}

Dermatophytosis, Epidemiology, Fungal Infection.

HOW TO CITE THIS ARTICLE: Mangla V. Epidemiological trend in superficial fungal infections at a tertiary centre in western Uttar Pradesh, India. J. Evolution Med. Dent. Sci. 2018;7(34):3754-3758, DOI: 10.14260/jemds/2018/843

\section{BACKGROUND}

Dermatophytoses have always been among the commonest infective dermatoses in India. A disease that was taken for granted and is now becoming a cause of anxiety and trepidation for the dermatologist. ${ }^{4}$ Among all the superficial fungal infections, dermatophytic infections have the highest prevalence in the developing countries with significant associated morbidity. ${ }^{5}$ Only under exceptional circumstances do they survive or proliferate in the deeper tissues of the body. ${ }^{6}$ It is impossible to tell how much of this widely perceived change is the product of primarily the host, agent, environmental or pharmacological factors and how much of it secondary to a change in health-seeking behaviour of the Indian patient.

There is a dire need for well-designed studies as well as more solid evidence for various issues pertaining to the dermatophytosis scenario in India. ${ }^{7}$ Comparison of studies done on superficial fungal infections in cities such as Kolkata, Ahmedabad and Chennai during different timeframes have revealed an increasing trend of dermatophytosis. $8,9,10,11,12,13$

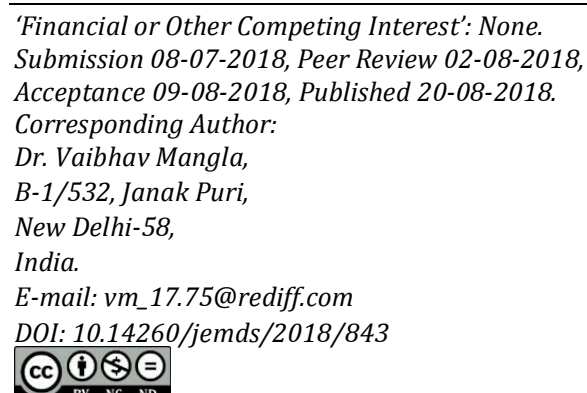

\section{MATERIALS AND METHODS}

This descriptive study was carried out in the Dermatology Department of a Medical College in the Rohilkhand region, which caters to the population from as far as Nepal.

A total of 600 patients were screened among the outpatients at the Dermatology Department of SRMS IMS, Bareilly from $1^{\text {st }}$ January 2016 to $30^{\text {th }}$ December 2016. The screening was done of patients who had a lesion with central clearing with advancing red, scaly, elevated border which may result in vesicles on the border of the affected area. Out of which 312 were found to be $\mathrm{KOH}$ positive cases, out of the 312 $\mathrm{KOH}$ positive cases 110 cases were not fulfilling inclusion criteria, 46 cases refused consent and 6 cases were of hyperhidrosis. Finally, 150 cases were enrolled in the study.

\section{Inclusion Criteria}

1. Clinically diagnosed case of dermatophytic infection.

2. Only $\mathrm{KOH}$ positive cases showing septate fungal hyphae will be selected.

3. Age $\geq 18$ years and $<65$ years (M).

4. Patient should be willing to give all socio-demographic information.

\section{Exclusion Criteria}

1. Uncooperative patients.

2. Patients with any type of malignancy.

IRB approval was taken and patients were included in the study after an informed and written consent. 


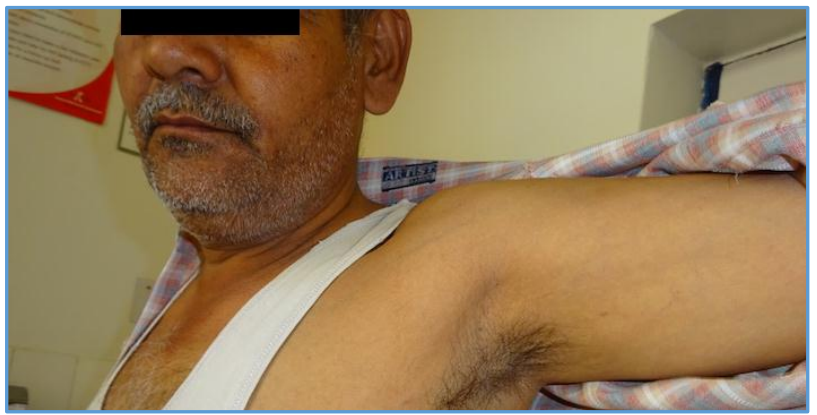

Figure 1. Non-Infected Site

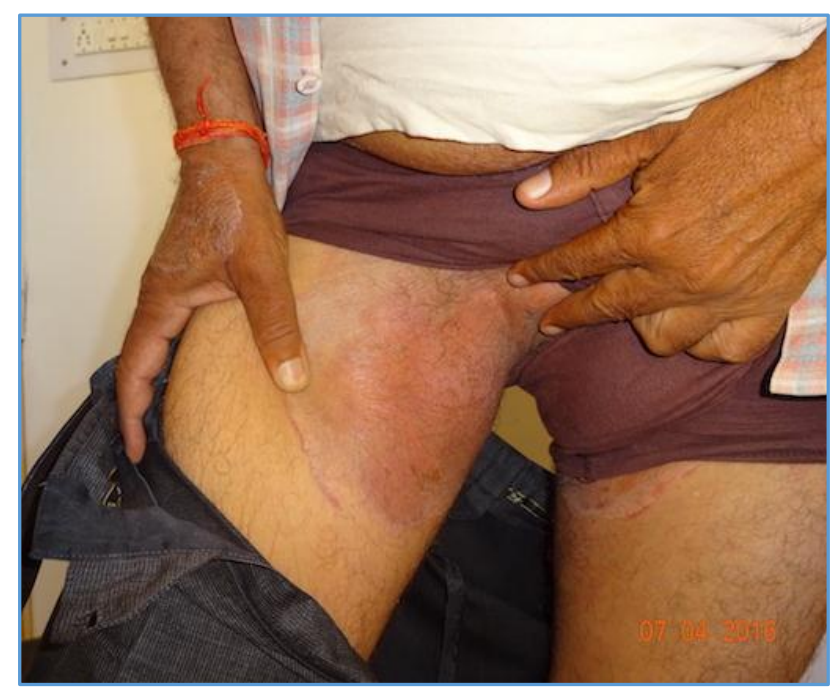

Figure 2. Infected Site

\section{RESULTS}

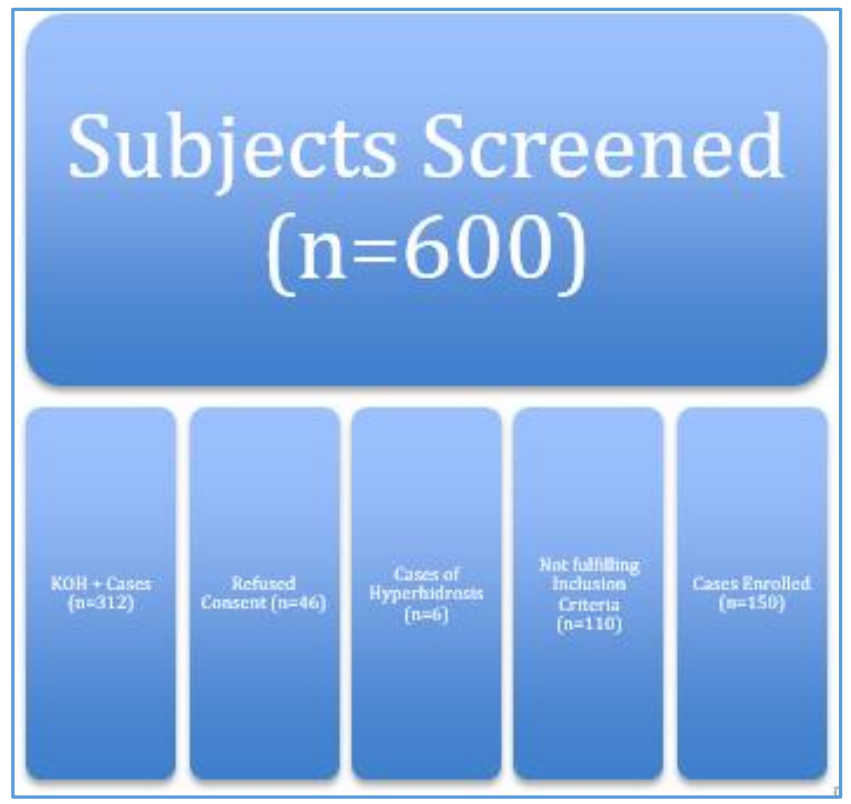

Figure 3. Monthly Prevalence

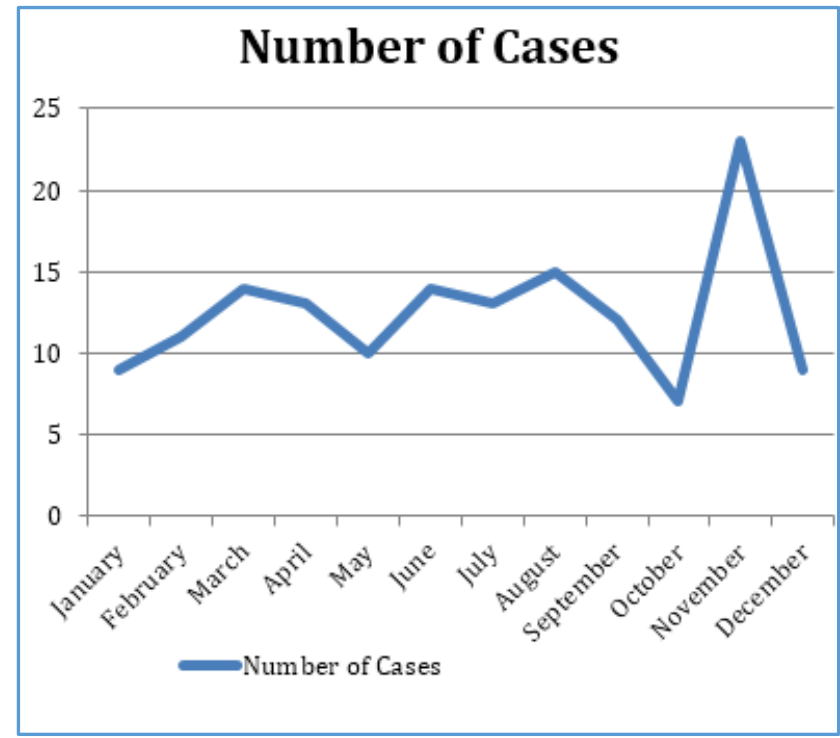

The highest incidence was in the month of November (23) followed by August (15) month.

\begin{tabular}{|c|c|c|c|}
\hline Sl. No. & Age-Group (in Years) & Numbers & $\%$ \\
\hline 1 & $18-20$ yrs. & 41 & 27.33 \\
\hline 2 & $21-30$ yrs. & 65 & 43.33 \\
\hline 3 & $31-40$ yrs. & 31 & 20.67 \\
\hline 4 & $41-50$ yrs. & 9 & 6 \\
\hline 5 & $51-60$ yrs. & 3 & 2 \\
\hline \multirow[t]{2}{*}{6} & 61-65 yrs. & 1 & 0.67 \\
\hline & Total $(n=150)$ & 150 & $100 \%$ \\
\hline \multicolumn{4}{|c|}{ Table 1. Age Profile } \\
\hline
\end{tabular}

Mean 27.79, Std. Dev. 9.59.

Most cases were in the Age Group of 21-30 years of age and least were in the Age Group of 61-70 years.

\begin{tabular}{|c|c|c|}
\hline Gender & No. & \% \\
\hline Male & 147 & 98 \\
\hline Female & 3 & 2 \\
\hline \multicolumn{3}{|c|}{ Table 2. Gender Profile } \\
\hline
\end{tabular}

Most of the cases were Male (98\%) and 2\% were Female.

\begin{tabular}{|c|c|c|}
\hline Married & 70 & 46.67 \\
\hline Unmarried & 80 & 53.33 \\
\hline \multicolumn{3}{|c|}{ Table 3. Marital Status } \\
\hline
\end{tabular}

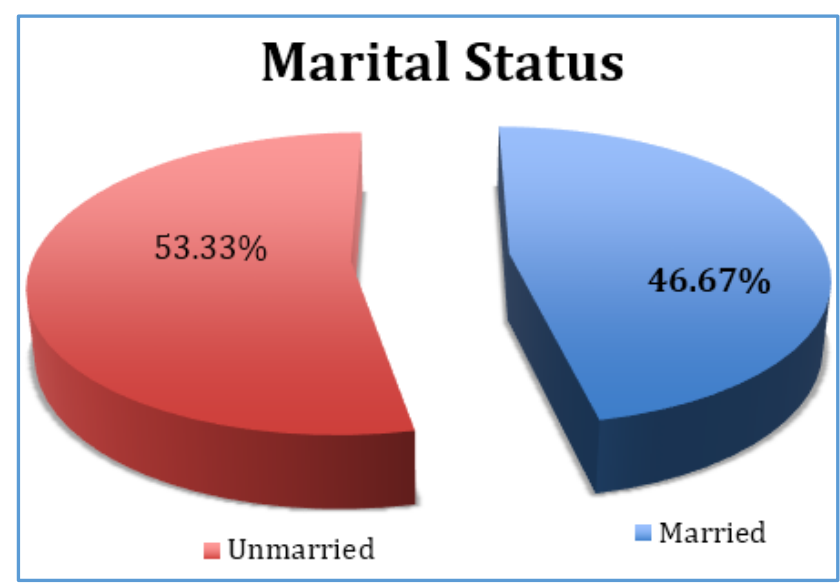

Figure 4 
Among individuals, $46.67 \%$ were married and unmarried were $(53.33 \%)$.

\begin{tabular}{|c|c|c|}
\hline & Present & Absent \\
\hline Number of Patients & 65 & 85 \\
\hline \% of Cases & $43.55 \%$ & $56.55 \%$ \\
\hline \multicolumn{2}{|c|}{ Table 4. Family History } \\
\hline
\end{tabular}

Most number of the cases (56.55\%) had no family history, while $43.55 \%$ of cases had positive family history.

\begin{tabular}{|c|c|c|c|c|}
\hline $\begin{array}{c}\text { Sl. } \\
\text { No. }\end{array}$ & Parameter & Mean \pm S.D. & $\begin{array}{c}\text { Maximum } \\
\left({ }^{\circ} \mathrm{C}\right)\end{array}$ & $\begin{array}{c}\text { Minimum } \\
\left({ }^{\circ} \mathrm{C}\right)\end{array}$ \\
\hline 1. & $\begin{array}{c}\text { Temperature } \\
\left({ }^{\circ} \mathrm{C}\right)\end{array}$ & $26.19 \pm 5.64$ & 39 & 12.05 \\
\hline 2. & Humidity (\%) & $56.36 \pm 27.69$ & 88.28 & 27 \\
\hline \multicolumn{4}{|c|}{ Table 5. Weather Profile* (Indian Meteorological } \\
Department Data)
\end{tabular}

As per IMD Data, Mean Temperature was 26.19 and Mean Humidity was 56.36 during the study period at Bareilly.

\begin{tabular}{|c|c|c|}
\hline & Total Cases & Percentage \\
\hline Service & 38 & $25.33 \%$ \\
\hline Student & 37 & $24.67 \%$ \\
\hline Labour & 32 & $21.33 \%$ \\
\hline Semi-Skilled & 25 & $16.67 \%$ \\
\hline Business & 17 & $11.33 \%$ \\
\hline Unemployed & 1 & $0.67 \%$ \\
\hline Total & $\mathbf{1 5 0}$ & $\mathbf{1 0 0 \%}$ \\
\hline \multicolumn{3}{|c|}{ Table 6. Job Profile } \\
\hline
\end{tabular}

Most of the cases were Service men (25.33\%), then were the Students (24.67\%) and least were Unemployed (0.67\%).

\begin{tabular}{|c|c|c|c|c|}
\hline $\begin{array}{c}\text { Sl. } \\
\text { No. }\end{array}$ & Parameters & Mean \pm S.D. & Maximum & Minimum \\
\hline 1 & $\begin{array}{c}\text { Height } \\
\text { (centimetres) }\end{array}$ & $168.39 \pm 7.29$ & 185 & 146 \\
\hline 2 & Weight (kgs) & $62.69 \pm 11.66$ & 108 & 42 \\
\hline 3 & $\begin{array}{c}\text { Body Mass } \\
\text { Index (BMI)* }\end{array}$ & $22.06 \pm 3.63$ & 33.7 & 15.57 \\
\hline \multicolumn{5}{|c|}{ Table 7. Anthropometric Profile } \\
\hline
\end{tabular}

Mean Height and Mean Weight were $163.39+/-7.29$ and $62.69+/-11.66$ respectively. Maximum participants had BMI in the range of 19-25. *BMI was calculated as Weight/Height ${ }^{2}$. Weight was taken in Kilograms and Height in Metres.

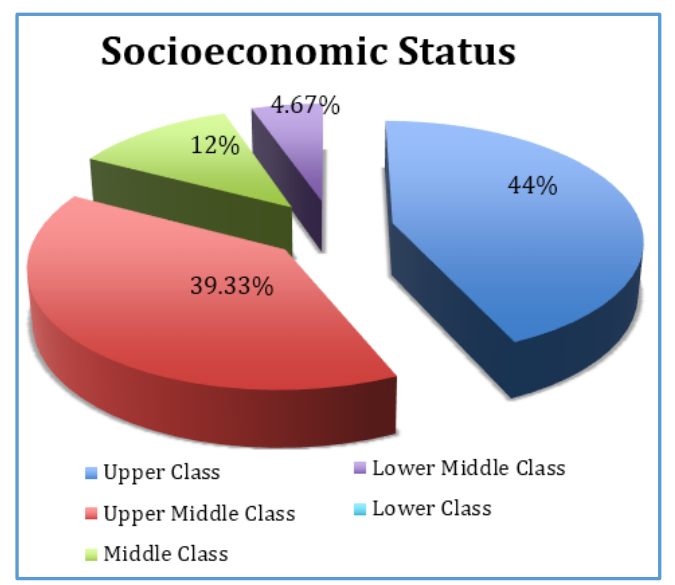

Figure 5. Socioeconomic Status
- As per Revised Modified BG Prasad Socioeconomic Scale.

- $\quad$ Most participants were in the Upper Class; Upper Class criteria was monthly per capita income more than Rs. 6346.

- $\quad$ There were no cases from the lower class (Monthly per capita income less than Rs. 951).

\begin{tabular}{|c|c|c|c|}
\hline Sl. No. & Level of Education & No. & $\%$ \\
\hline 1 & Postgraduate and above & 15 & 10 \\
\hline 2 & Graduate & 49 & 32.67 \\
\hline 3 & Attended School & 72 & 48 \\
\hline \multirow[t]{2}{*}{4} & Uneducated & 14 & 9.33 \\
\hline & Total & 150 & $100 \%$ \\
\hline
\end{tabular}

Maximum number of participants (72) attended at least school and least number (14) were uneducated.

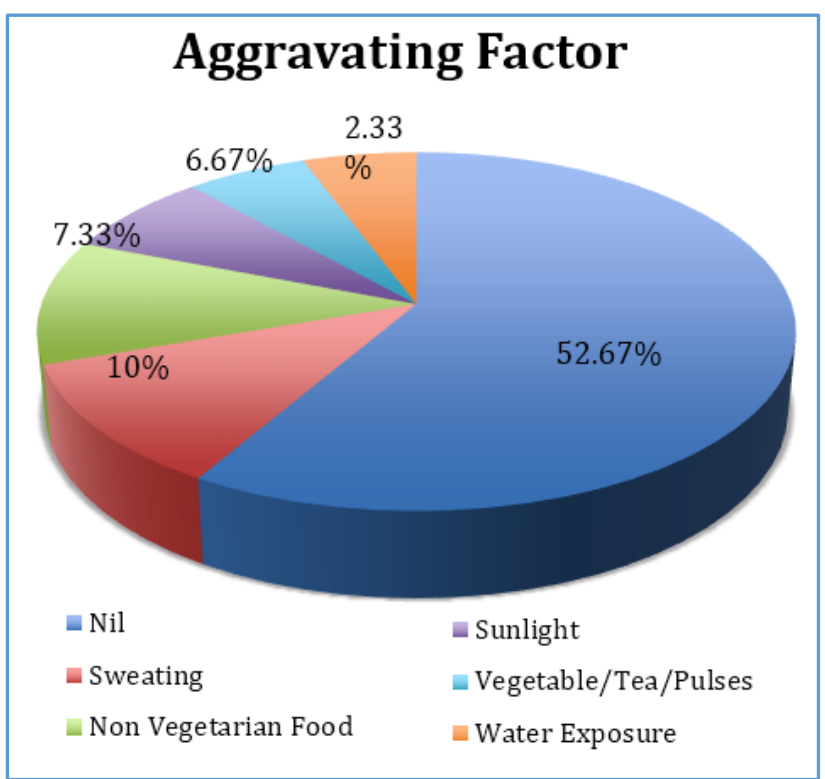

Figure 6. Common Aggravating Factors

Majority of patients (52.67\%) had no aggravating factor and least (2.33\%) had water exposure as aggravating factor.

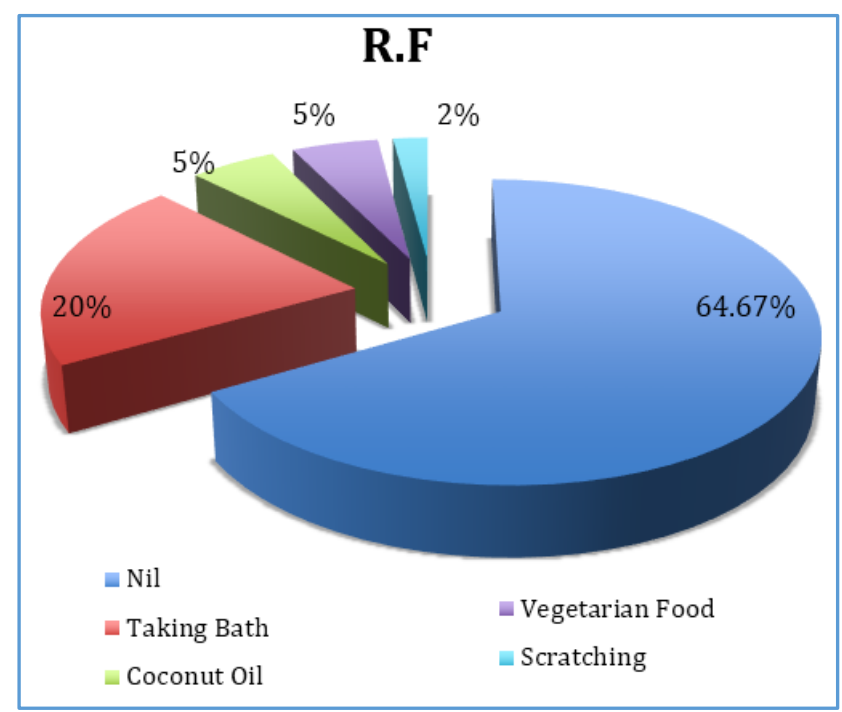

Figure 7. Common Relieving Factors 


\begin{tabular}{|c|c|c|}
\hline & Vegetarian & Non-Vegetarian \\
\hline Number of cases & 80 & 70 \\
\hline Percentage of cases & $53.6 \%$ & $46.4 \%$ \\
\hline \multicolumn{2}{|c|}{ Table 9. Food Habits } \\
\hline
\end{tabular}

Maximum number (53.6\%) of cases were Vegetarian and least number (46.4\%) were Non-Vegetarian.

\begin{tabular}{|c|c|c|}
\hline & Number of Cases & Percentage of Cases \\
\hline Topical Steroid & 38 & $25.46 \%$ \\
\hline Systemic Steroid & 15 & $10 \%$ \\
\hline \multicolumn{2}{|c|}{ Table 10. Steroid Application Profile } \\
\hline
\end{tabular}

$25.46 \%$ of cases had history of topical steroid application, whereas only $10 \%$ of cases had taken systemic steroids.

\section{DISCUSSION}

In past studies, it has been observed that axilla and groin are the most commonly affected sites due to increased sweat production and occlusive morphology of the location.

The distribution, frequency and aetiological agents of dermatophytosis vary according to the geographic region studied, the climatic variations, the socioeconomic level of the population, the time of study, the presence of domestic animals and age of the individual has already been proven. ${ }^{14}$

In our study which included factors like Age, Sex, Residence, Aggravating factors, Relieving factors and Outside treatment history along with any associated disease was a very vast study, which included all possible parameters including BMI and weather.

The clear-cut peaks of Dermatophytosis in the present study are in the months of November and August, whereas in a previous study on Dermatophytosis in Munich. ${ }^{15}$ The clearcut peaks were in the months of January and September. In a previous study on superficial dermatophytoses in Asia done by KJ Rhim and JH Kim in 1978, it was found that 'the age group of 20 - 29 years shows the highest incidence.'16

Most participants in the present study were of the age group 21 - 30 years and constituted $42.67 \%$ of total cases followed by the 10 - 20 years' age group, which consisted only of adults above 18 years of age. Such individuals were 41 out of total of 150 cases constituting $27.33 \%$ of participants. These findings are consistent with the findings of KJ Rhim and JH Kim followed by 31 - 40 years' age group, which had $20.67 \%$ of total participants, 41 - 50 years' age group had $6 \%$ participants and 51 - 60 years' age group and 61 - 70 years' age group having only $2 \%$ and $1.33 \%$ participants respectively. Majority of past studies from India have reported a preponderance of patients aged $<40$ years. ${ }^{2,3,7,12,17-19}$

The probable reason for higher prevalence in this group could be that the individuals in this group are often most active because of their involvement in the outdoor activities such as studies, jobs etc. 18

The study had $98 \%$ of cases as Males in comparison to Females, who constituted only $2 \%$ of cases. This disparity was largely due to reluctance of Female patients to participate in the study, as the principal investigator was a male postgraduate student and females were not willing to let examination of their groin and axilla. Such females were excluded from the study as per exclusion criterion.

Fungal infections are relatively less common in women. This may be explained by them being relatively less exposed to an environment conducive to the spread of organisms.
In past studies from India done on the topic of dermatophytosis, males outnumbered females 8,12 to the tune of males comprising $85.1 \%$ of total patients in one study by Bhatia et al. ${ }^{18}$ This may be due to the differences in occupational exposure of both the sexes, as males are more involved in construction and other works. ${ }^{18}$ Exception to this finding was a study done in North India, where the Male: Female ratio was found to be $1: 1.19$

Past studies have shown a significant difference in alpha diversity between men and women on virtually all body sites including palm. ${ }^{20}$ In this study positive family history was seen is $43.55 \%$ of cases, which is rather low compared to a previous study in Eastern India where positive family history was seen in $83.84 \%$ cases. $^{5}$

Most of the cases enrolled were from India, but 5 cases were from Nepal as it is neighbouring the Rohilkhand region. Among Indian cases, 135 were from Uttar Pradesh constituting $90 \%$ of all participants and rest 10 cases $(6.67 \%)$ were from Uttarakhand. Majority of patients were from a rural background (55.33\%) and urban patients were only $44.67 \%$ of all. These findings are similar to those reported by Lavanya et al, who reported $54 \%$ of their study patients belonging to a rural background. ${ }^{17}$ This is in contrast to a past study by Gupta et al, where majority of patients were from the urban background as their study institute was located in a city. ${ }^{19}$

Our institute caters to a predominant rural population and hence majority of patients hailed from a rural background in the present study. The relatively increased incidence in rural populations may be due to a low standard of health education, overcrowding, poor hygiene and close personal and animal contact. ${ }^{21}$ The relatively different outdoor and indoor occupations in rural and urban background respectively may alter skin conditions, hence the bacteria that reside there.20

In this study, maximum number of patients were either service going or student classed. This is similar to the past study done by Monika et al, where maximum were service class or were students. ${ }^{19}$ On the contrary in a previous study done in Tamilnadu, maximum number of participants were manual labourers (54.50\%). ${ }^{22}$

The patients with a history of topical steroid application were 38 , probably the number could be higher as most of the patients did not know what they had applied or what they had taken orally. In the study done by Dash et al, treatment by past application of topical steroids and mixed cream was seen in $121(61.11 \%)$ patients. ${ }^{5}$ In a previous study by Dutta et al, pharmacists were responsible for $78 \%$ of tinea incognito cases, and betamethasone dipropionate was the most common drug used. ${ }^{23}$ Sweating (10\%) was the most common aggravating factor and taking bath $(20 \%)$ was the most common relieving factor.

\section{CONCLUSION}

Our study is a comparative analysis with studies done in other parts of the country to the trends in Western Uttar Pradesh and Uttarakhand on dermatophytosis and superficial fungal infection.

The Impact of age, Living conditions, Weather, BMI and personal factors on susceptibility to and duration of Dermatophytic/Superficial fungal infections was elucidated in India's most populous state. ${ }^{24}$ 
Subjects in the age group 21-30 years, service personnel and subjects from upper socio-economic status were more predisposed to superficial fungal infections.

\section{REFERENCES}

[1] Lakshmanan A, Ganeshkumar P, Mohan SR, et al. Epidemiological and clinical pattern of dermatomycoses in rural India. Indian J Med Microbiol 2015;Suppl 33:134-6.

[2] Ramaraj V, Vijayaraman RS, Rangarajan S, et al. Incidence and prevalence of dermatophytosis in and around Chennai, Tamil Nadu, India. Int J Res Med Sci 2016;4(3):695-700.

[3] Adefemi SA, Odeigah LO, Alabi KM. Prevalence of dermatophytosis among primary school children in Oke-oyi community of Kwara state. Nigerian Journal of Clinical Practice 2011;14(1):23-8.

[4] Panda S, Verma S. The menace of dermatophytosis in India: the evidence that we need. Indian J Dermatol Venereol Leprol 2017;83(3):281-4.

[5] Dash M, Panda M, Patro N, et al. Sociodemographic profile and pattern of superficial dermatophytic infections among paediatric population in a tertiary care teaching hospital in Odisha. Indian J Paediatr Dermatol 2017;18(3):191-5.

[6] Chastain MA, Reed RJ, Pankey GA. Deep dermatophytosis: report of 2 cases and review of the literature. Cutis 2001;67(6):457-62.

[7] Verma SB. Sales, status, prescriptions and regulatory problems with topical steroids in India. Indian J Dermatol Venereol Leprol 2014;80(3):201-3.

[8] Grover WC, Roy P. Clinico-mycological profile of superficial mycosis in a hospital in North-East India. Med J Armed Forces India 2003;59(2):114-6.

[9] Das K, Basak S, Ray S. A study on superficial fungal infection from West Bengal: a brief report. J Life Sci 2009;1(1):51-5.

[10] Nawal P, Patel S, Patel M, et al. A study of superficial mycosis in tertiary care hospital. Natl J Integr Res Med 2012;3(1):90-3.

[11] Chudasama V, Solanki H, Vadasmiya M, et al. A study of superficial mycosis in tertiary care hospital. Int J Sci Res 2014;3:222-4.

[12] Kannan P, Janaki C, Selvi GS. Prevalence of dermatophytes and other fungal agents isolated from clinical samples. Indian J Med Microbiol 2006;24(3):212-5.
[13] Narasimhalu CRV, Kalyani M, Soumender S. A crosssectional, clinico-mycological research study of prevalence, aetiology, speciation and sensitivity of superficial fungal infection in Indian patients. J Clin Exp Dermatol Res 2016;7(1):1-10.

[14] Al-Rubiay KK, Al-Rubiay LK. Dermatoepidemiology: a household survey among 2 Urban areas in Basra City, Iraq. Int J Dermatol 2006;4:1-4.

[15] Zienicke HC, Korting HC, Lukacs A, et al. Dermatophytosis in children and adolescents: epidemiological, clinical, and microbiological aspects changing with age. The Journal of Dermatology 1991;18(8):438-46.

[16] Rhim KJ, Kim JH, Shin S. A clinical and mycological study of superficial dermatophytosis. Korean J Dermatol 1978;16(6):435-42. Korean.

[17] Lavanya V, Solabannavar SS. Prevalence and Socioeconomic correlation of dermatophytes isolated from clinical samples in a tertiary care centre in south India. Asian J Adv Basic Sci 2015;4(1):1-4.

[18] Bhatia VK, Sharma PC. Epidemiological studies on dermatophytosis in human patients in Himachal Pradesh, India. Springerplus 2014;3:134.

[19] Monika, Gupta SK, Chinna DK, et al. Clinico-Mycological correlation of superficial fungal infect ions. The Gulf Journal of Dermatology and Venereology 2016;23(1):613.

[20] Rosenthal M, Goldberg D, Aiello A, et al. Skin microbiota: Microbial community structure and its potential association with health and disease. Infect Genet Evol 2011;11(5):839-48.

[21] Bose S, Kulkarrni SG, Akhter I. The incidence of Tinea capitis in a tertiary care rural hospital - a study. Journal of Clinical and Diagnostic Research 2011;5(2):307-11.

[22] Mahalakshmi R, Apoorva R, Joshua J. Dermatophytosis: clinical profile and association between sociodemographic factors and duration of infection. Int J Res in Dermatology 2017;3(2):282-5.

[23] Dutta B, Rasul ES, Boro B. Clinico-epidemiological study of tinea incognito with microbiological correlation. Indian J Dermatol Venereol Leprol 2017;83(3):326-31.

[24] https://www.census2011.co.in/states.php 